\title{
Rafael de Buen Lozano: el periplo americano de un exilado republicano español ${ }^{1}$
}

\section{Arturo Taracena Arriola ${ }^{2}$}

Recepción: 2 de setiembre de 2015 / Aprobación: 15 de octubre de 2015

\section{Resumen}

Este es un ejercicio por recuperar la memoria histórica de republicanos españoles que vivieron en Centroamérica a partir de la biografía del biólogo republicano español Rafael de Buen Lozano. Militante en España primero de Acción Socialista y, luego, del Partido Comunista Español por medio de artículos sobre la familia De Buen, entrevistas, cartas dirigidas a su hija Rafaela de Buen López y otros materiales durante las estancias en su país, Argelia, Centroamérica, Venezuela y México. Se destaca su papel como científico en las distintas universidades en que trabajó, como miembro del Estado Mayor del Ejército republicano durante la Guerra Civil Española, como miembro de las Casas de la República en el exilio, especialmente durante su permanencia en Guatemala entre 1945 y 1954, la que con la caída del gobierno de Jacobo Arbenz lo obligó a vivir un nuevo exilio.

\section{Palabras clave}

República española en el exilio; inmigración América Latina; Rafael de Buen Lozano; científicos españoles

\section{Abstract}

This article is an exercise to recover the historical memory of Spanish Republicans who lived in Central America, from the biography of the Republican Spanish biologist Rafael de Buen Lozano, militant first of Socialist Action in Spain and then of Spanish Communist Party, through articles on De Buen family, interviews, letters to her daughter Rafaela de Buen Lopez, and other materials during their stay in Spain, Algeria, Central America, Venezuela, and Mexico. He played a remarkable role as scientist in several universities, as a member of Staff of the Republican Army during the Spanish civil war, and as a member of the Houses of the Republic in exile, especially during his stay in Guatemala between 1945 and 1954, which forced him to live a new exile due to the fall of government of Jacobo Arbenz.

$1 \quad$ El texto es parte de una serie de biografías de emigrados republicanos españoles a Guatemala en el contexto de la redacción de mi investigación en el Centro Peninsular en Humanidades y Ciencias Sociales (CEPHCIS), Mérida, Yucatán, de la Universidad Nacional Autónoma de México (UNAM) sobre Guatemala y la República Española en el exilio, 1944-1954.

2 Guatemalteco. Doctor en Historia por la École des Hautes Études en Sciences Sociales, París. Investigador titular definitivo del CEPHCIS, UNAM. Correo: ataracena@yahoo.com 


\section{Keywords}

Spanish Republic in exile; inmigration; Latin America; Rafael de Buen Lozano; Spanish scientists

\section{Resumo}

Este é um exercício de recuperar a memória histórica de republicanos espanhóis que viveram na América Central, a partir da biografia do biólogo republicano espanhol Rafael de Buen Lozano, militante na Espanha, primeiro de ação socialista e depois do Partido Comunista Espanhol; por meio de artigos sobre a familia De Buen, entrevistas, cartas dirigidas a sua filha Rafaela de Buen López e outros materiais durante suas estadias no seu país, Argélia, América Central, Venezuela e México. Destaca-se seu papel como cientista nas distintas universidades em que trabalhou, como membro do Estado Maior do Exército republicano durante a guerra civil espanhola, como membro das Casas da República no exilio, especialmente durante sua permanência na Guatemala entre 1945 e 1954, na qual com a queda do governo de Jacobo Arbenz, foi obrigado a viver em novo exilio.

\section{Palavras-chave}

República espanhola no exílio; imigração América Latina; Rafael de Buen Lozano; cientistas espanhóis

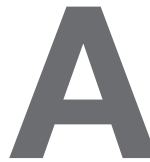

diferencia de México, Venezuela o Chile, en Centroamérica pocos son los trabajos que investigan las características de la inmigración y el asilo republicano español en el istmo, así como el papel que jugaron aquellos republicanos que permanecieron por varios años en los diferentes países que lo integran ${ }^{3}$. Permanencia que se vio siempre condicionada por el hecho de que, salvo Costa Rica y Panamá, a finales de los años treinta e inicios de los cuarenta del siglo pasado, los gobiernos centroamericanos estaban dirigidos por dictaduras militares personalizadas abiertamente aliadas del régimen franquista. Es cierto que con la entrada de Estados Unidos en la II Guerra Mundial, dichos regímenes dictatoriales cayeron (Guatemala, Honduras y El Salvador) o se vieron obligados a plantearse una apertura política impulsados por los valores democráticos de la Carta del Atlántico firmada entre Estados Unidos e Inglaterra en agosto de 1941. Hechos que permitieron la permanencia en suelo centroamericano de algunos cientos de inmigrantes republicanos españoles, quienes ejercieron diversos oficios para sobrevivir de acuerdo con su profesión, militancia política, relaciones sociales y fortunas personales anteriores. El caso del doctor Rafael de Buen Lozano es un ejemplo de ello, con

3 En Costa Rica sobresale la obra pionera de Mario Oliva Medina (2008), Los intelectuales y las letras centroamericanas sobre la Guerra Civil Española, México; el artículo de Luis Luján Muñoz (1944) "La Revolución del 20 de Octubre de 1944 y los republicanos españoles en Guatemala" y el libro de quien escribe (2014) estas líneas La polémica entre Eugenio Fernández Granell, la AGEAR y el Grupo Saker-ti: Desencuentros ideológicos durante la 'primavera' democrática guatemalteca. 
el plus de haber realizado, en aras de asentarse en América y desarrollar sus capacidades profesionales y sus tareas militantes, el periplo de buena parte de los países del área circuncaribe continental (México, Guatemala, Nicaragua, Costa Rica, Panamá, Cuba y Venezuela).

\section{Las dos Españas}

Rafael de Buen Lozano nació en La Garriga, Barcelona, el 10 de julio de 1891 y falleció en Morelia, México, el 30 de mayo de 1966. Era hijo del afamado biólogo y oceanógrafo Odón de Buen del Cos y Rafaela Lozano. En 1889, Odón de Buen pasó a ser profesor de biología de la Universidad de Barcelona, puesto que ocupó hasta 1911, una carrera que habrían de seguir sus hijos Rafael y Fernando. Ese año se casó con Rafaela Lozano, quien era hija del periodista Fernando Lozano Montes, director del periódico Los Dominicales del Libre Pensamiento (De Mónaco, marzo 2012).

Rafael de Buen entró a estudiar en la Universidad de Barcelona, de la que se doctoró en 1912 con la tesis «Estudio de los fondos marinos», especializándose posteriormente en biología y oceanografía. De 1913 a 1914 fue conservador del Laboratorio de Biología Marina de Málaga. En abril de 1914 ganó por oposición la cátedra de Mineralogía y Botánica de la Sección de Ciencias de Cádiz y

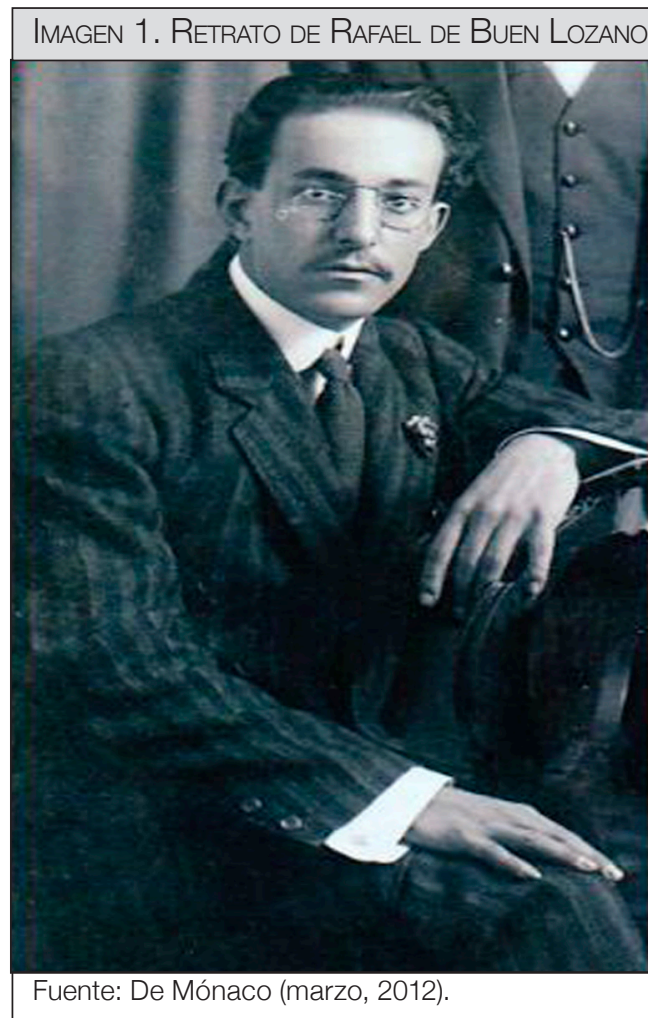
Sevilla, y comenzó a trabajar como jefe de la sección oceanográfica del Instituto Español de Oceanografía. En esa época, también prestó sus servicios en el Instituto Oceanográfico de Mónaco, donde cooperaba su padre. A inicios de la década de 1920 se casó con Francisca Luisa Paquita López de Heredia Aransáez, nacida en Haro, provincia de Logroño en 1888, con la cual tuvo cuatro hijos. La mayor fue Rafaela De Buen López, que nació en 1921 y quien me ha proporcionado un importante testimonio para realizar esta biografía.

Desde enero de 1924, Rafael De Buen Lozano ejerció como catedrático en la Universidad Central de Madrid. Asimismo, fungió como vocal de la Liga Española de los Derechos del Hombre y, desde diciembre de 1933, fue miembro de la Federación Española de Trabajadores de la Enseñanza afiliada a la Unión 
General de Trabajadores (UGT). Entonces pertenecía al Partido Radical Socialista hasta que en agosto de 1935 se afilió a la Asamblea Socialista -A.S.- de Madrid. Fue jefe de la Sección de Archivos de la citada A.S. y presidente, en 1936, del Círculo Socialista de Buenavista (Fundación Pablo Iglesias, s.f.).

Durante la Guerra Civil (1936) fue miliciano y presidente del Comité del Frente Popular en la Colonia de la Cruz del Rayo de Madrid. Sin embargo, pronto pasó a militar en el Partido Comunista de España (PCE) y a trabajar en el Estado Mayor del Ministerio de la Guerra, donde el año de 1937 lo enviaron a uno de los cuerpos del ejército de tierra en la Sierra de Madrid. Desde allí le escribió a doña Rafaela el 20 de septiembre indicándole su presencia en dicho frente de guerra (R. Buen Lozano, 1937). En esa coyuntura, Rafael de Buen Lozano se separó de su esposa Paquita, para entonces enfermera en Madrid y se juntó con Matilde Laffin una amiga de la familia. En 1934, Paquita López de Heredia se había afiliado al PSOE en la agrupación madrileña y perteneció al Sindicato de Oficios Varios de la UGT desde el año 1936. Durante la Guerra Civil, ella ejerció su profesión. Viajó a México en el Nyassa en 1942. En este país trabajó como enfermera en jefe del Instituto de Histología Aplicada de la capital mexicana. Posteriormente, a instancias de sus hijos, se trasladó a Chile, donde moriría en 1972 (Fundación Pablo Iglesias, s.f.).

El inicio de la guerra civil sorprendió a Odón de Buen y Cos en Palma de Mallorca, pues trabajaba en el laboratorio marino de la isla, siendo detenido por los sublevados y enviado a prisión, de donde fue liberado luego de un año a raíz de la presión de los cónsules de Dinamarca y Gran Bretaña y por intercambio de la hija y la hermana de Miguel Primo de Rivera. Igualmente, el menor de sus hijos, Sadí de Buen Lozano, fue apresado por los franquistas en Sevilla, donde trabajaba como médico, siendo fusilado el 3 de septiembre de ese mismo año (De Mónaco, marzo 2012).

En prevención, al darse el sitio de Madrid, Rafaela de Buen López fue enviada por sus padres a Barcelona, junto a otros 80 alumnos del Instituto de Madrid, los que fueron alojados en el Palacio de Pedralbes. Allí cuidarían de infantes. Luego se adhirió a la Unión de Muchachas en 1938 cuando estaba en el último año de bachillerato con el fin de atender heridos, especialmente de las Brigadas Internacionales, a las cuales despidió junto a varios miles de españoles reunidos en la avenida Diagonal de Barcelona el 1 de noviembre de ese año. Ella guarda un dibujo a lápiz que le ofrecieron internacionalistas puertorriqueños y cubanos en el que una estrella, un puño y el busto de un brigadista están sobremontados en una bandera española republicana. Abajo se lee el lema: "Símbolo de la solidaridad de los Internacionales y de que seguiremos luchando hasta la victoria final”. Estaba firmado por Ramón López, cubano; Humberto Álvarez, cubano; Roberto Bertrán, cubano; M. A. Estella,

4 Véase también: Guerra, 2003, p. 637. 
puertorriqueño y Emiliano Merin, puertorriqueño ("Cuba y Puerto Rico" dibujo a mano, Barcelona, 1938) ${ }^{5}$. Por esa época, doña Rafaela entró a trabajar en la sede del Ministerio de la Defensa en esa ciudad. "Pedro hizo la guerra, mis tres hermanos hicieron la guerra", me confió al hablar de su hermano mayor, quien había nacido en 1916.

Estuvo en Madrid. Pedro estaba en el Ejército del Este. Héctor, que era el segundo, fue hecho prisionero en la última de las campañas y pasó varios meses -no sé cuanto tiempo- preso, en Madrid, con torturas medianas, porque no había tanto refinamiento como lo ha habido después. Pero a puñetazos le botaron los dientes, a puñetazos así en la boca, porque había sido preso estando en el ejército. Mario estaba en Madrid, pero simplemente cayó cuando Madrid cayó, entre miles de personas. Entonces lo tuvieron en una especie, así, de campo de concentración, pero un tío mío que tenía influencias en Barcelona, que fue Decano de Leyes en Barcelona, logró sacarlo y se lo llevó... Mi hermano se quedó viviendo con este tío, estudió Ingeniería y llegó a Chile después (R. de Buen López, comunicación personal, julio de 2014) ${ }^{6}$.

El 9 de septiembre de 1937, desde Madrid, Rafael de Buen Lozano le escribió la siguiente carta a su hija:

Recibí tu última carta por la que veo que trabajas en el Ministerio de la Defensa, aunque no me dices en qué sección. Me perece bien que trabajes cuanto puedas y te des cuenta de que los instantes que vivimos, lo primero es hacer algo por cooperar a nuestro triunfo. Olvidemos incluso nuestros estudios y la labor que hacíamos en la paz para dedicarnos con el mayor entusiasmo a los trabajos de la guerra. No debemos dejar de pensar nunca en los que lo dan todo en las trincheras para combatir a los traidores y extranjeros que han mandado los gobiernos fascistas y lo menos que podemos hacer para ser dignos de ellos es trabajar como sea necesario. No por afán de buscar un medio de vida, sino por deseo de prestar la mayor ayuda posible. Nos han tocado vivir momentos difíciles, procura hacerte digna de ellos y saca las enseñanzas necesarias para no ser el día de mañana una muñeca frívola, sino una mujer como es debido (R. de Buen López, comunicación personal, julio de 2014).

Para entonces, doña Rafaela militaba ya en el Partido Socialista Unificado. Al caer Barcelona, ella se trasladó a Francia. Peripecia que describe de esta manera luego de que con su familia logró pasar por el puerto fronterizo de Le Perthus:

A nosotros que pasamos pronto, nos tocó ver pasar la frontera a toda esta gente. Pasaba camino a un campo de concentración porque no tenían familia ni nadie que les diera de comer... Era bastante impresionante ver esa fila de personas, de hombres, era realmente penoso. Además, nosotros, con mi madre y mi tía [Berta López de Heredia] y mi primo [Sadí De Buen López], que habíamos primero

$5 \quad$ Véase al respecto: Baumann, 2009.

6 Agradezco a Marilyn Leyva la transcripción de la entrevista. Las cartas mencionadas en este ensayo fueron leídas por doña Rafaela ante la grabadora, menos la del 14 de septiembre de 1954, de la que me permitió hacer una copia. 
tratado de pasar no por la costa, no pudimos pasar porque habían tantos carros tirados, que la gente dejaba el auto, porque con ellos no dejaban pasar a Francia. Entonces se formó un atochamiento de autos abandonados. Por ahí no pudimos pasar, entonces tuvimos que volver de Cerbère y de ahí a Le Perthus. Por suerte, en Francia se había formado un comité de ayuda a los intelectuales españoles en Toulouse. Entonces, de ahí ya estaba yo en Francia. Nos tenían que dar de comer y un colchón dónde dormir. En los que llamaban en Francia Caserne de Pompiers, los cuarteles de bomberos, que ya a los bomberos les habían construido mejores y se habían ido y ahí estuvimos en Toulouse varios meses hasta que habían nombrado a Pablo Neruda cónsul en Francia para traer españoles a Chile. El primer [barco] organizado fue el Winnipeg. Mi abuelo [Odón de Buen], me había conseguido una beca para Columbia University y fue justo cuando se declaró la guerra europea y se suprimieron las compañías navieras, en un momento en que no hubo [transporte marítimo] y me quedé sin poder ir. En el barco Formosa, yo llegué en diciembre de 1939; llegué a Chile en la Navidad del 39, pero el barco había demorado casi un mes en llegar. Yo creo que salimos a fines de noviembre. Bueno, es que sólo veníamos 50 personas en el Formosa, pero los que llegaron aquí son todavía amigos míos, los que todavía viven. Con Cristian Aguadé venía en el Formosa, que después se casó con Roser Bru [él empresario y ella pintora, ambos catalanes refugiados (R. de Buen López, comunicación personal, julio de 2014).

El barco, que era un carguero, había salido del puerto francés de Le Havre y según Verena Vrsalovic, tocó suelo chileno el 19 de diciembre de ese 1939 (Vrsalovic, 2004). Antes de la caída de Madrid a finales de marzo de 1939, como muchos importantes dirigentes comunistas, Rafael De Buen Lozano salió para Valencia. El 28 de marzo partió del puerto de Alicante en el Stanbrook rumbo a Argelia, a donde llegó el día 30. Según las cartas que guarda doña Rafaela, su padre le escribió cartas en papel membretado del "Ejército del Centro, Estado Mayor: servicios" desde la ciudad de Orán, entre el 13 de agosto de 1939 hasta abril de 1940.

\section{La América ignota}

De Orán, De Buen Lozano salió hacia América, posiblemente vía México (Fundación Pablo Iglesias, s.f.), pues el 26 de agosto de ese año de 1940 le comunicó que ya residía en Nicaragua. En este país se instaló en la ciudad de Granada, comentándole:

El día 5 [de julio] entré en Nicaragua y desde el primero de este mes [o sea, agosto], estoy colocado por el Ministerio de Instrucción Pública como subdirector del Instituto Nacional de Oriente y profesor de las asignaturas de historia y natural. Este país no tiene recursos, imagina que el sueldo que recibo es justo para vivir... Tengo al fin en que ocuparme y he logrado liberarme de la catástrofe en Francia (R. de Buen López, comunicación personal, julio de 2014).

Producto de su estancia en este país fue su ensayo El Gran Lago de Nicaragua y su estudio, aparecido en 1940. El 24 de julio de 1941, Rafael de Buen Lozano escribió ya desde San José de Costa Rica, señalando que estaba: 
contento, es una población muy pequeña, cien mil habitantes, pero muy bonita situada en un valle entre montañas a unos 1200 metros de altura, el clima es delicioso, me parece mentira la temperatura fresquita, después del calor que pasamos en Nicaragua. Trabajo en la Universidad, donde explico Biología en la Facultad de Ciencias ${ }^{7}$ y además en un laboratorio del Ministerio de Salubridad, donde estoy dedicado más que nada al estudio de alimentos... Tengo los dos cargos, puedo vivir con cierta tranquilidad y desde luego mucho mejor que en Granada, como veis he salido ganando entonces (R. de Buen López, comunicación personal, julio de 2014).

Para entonces su hermano Demófilo y su cuñada Paz Lozano estaban en este país centroamericano (Fundación Pablo Iglesias, s.f.). Producto de sus investigaciones alimentarias fue el informe elevado al Consejo de Nutrición de la Secretaría de Salubridad Pública y Protección Social intitulado "Bases de una política de alimentación", publicado en 1941 en la revista Salud, No. 6, San José, Costa Rica, pp. 10-12 (Giral. 1994, p. 157). En julio de 1943, continuaba en San José y le comentaba a la hija:

Sigo mis trabajos como siempre, además de mi labor en la Universidad y en Salubridad, me estoy ahora ocupando de cuestiones de pesca y también tengo que dedicar mucho tiempo a los trabajos relacionados con nuestra lucha en relación con España. Colaboro con todas las asociaciones antitotalitarias, en las organizaciones de republicanos españoles, etc. De manera que no tengo ni un momento libre. También recibo muchas revistas y periódicos nuestros, que leo con el interés que puedes figurarte en la dicha de estar enterado de todo lo que se hace en América. De Chile me mandan La Verdad de España, aunque eso llega con mucho retraso. Supongo recibirías un ejemplar de un librito sobre nutrición que me han publicado aquí y del que ya tienen un ejemplar. Soy el Secretario del Consejo Nacional de Nutrición y me encargaron de escribir un tratado que sirviera para divulgar los problemas liados con la alimentación del hombre... No me ha sentado mal mi instancia en estas tierras, desde luego me he repuesto mucho desde que llegué, pero después de la guerra en España y las fatigas en Argelia, necesitaba un período de buena alimentación y la tranquilidad (R. de Buen López, comunicación personal, julio de 2014).

El libro en cuestión es Nutrición humana y los problemas que plantea (1943). En abril de 1944, De Buen Lozano escribió desde San José que iría a Panamá, donde ahora vivía su hermano Demófilo, pues "creo que la Universidad de Panamá me encargará también algunas conferencias sobre biología. Hace tiempo que no salgo de Costa Rica, de manera que puede que el viaje me distraiga" (R. de Buen López, comunicación personal, julio de 2014). Ese mismo año, Rafael de Buen partió para México y entró a trabajar como asesor del Ministerio de la Marina, cargo que ocupó hasta 1945. Allí aprovechó para publicar el tratado Biología (México, Editorial Minerva, 1944). Pero, todo indica que, a raíz de la Revolución del 20 de Octubre de 1944 y la asunción del presidente Juan José Arévalo en abril de 1945, este decidió desplazarse a Guatemala, entrando a

$7 \quad$ Se trata de la Facultad de Ciencias de la recién fundada Universidad de Costa Rica. 
trabajar a finales del año como jefe de investigaciones químico-biológicas en la Universidad de San Carlos (Amo y Shelby, 1950, p. 21).

Por la documentación de la Casa de la República Española de Guatemala sabemos que se incorporó a esta el 5 de diciembre de 1946, como socio numerario número 35, convirtiéndose en un importante miembro y un animador del Ateneo "Federico García Lorca" (Archivo General de la Administración, España. Libro de Actas de la Casa de la República Española, 42, fols. 31 y 32, 5 de diciembre de 1946). De acuerdo con el testimonio de Alfredo Guerra Borges, a finales del año de 1946, Rafael de Buen Lozano puso a este y a otros jóvenes del partido Vanguardia Nacional (fundado en 1944) en contacto con los obreros que pertenecieron a la Confederación de Trabajadores de Guatemala, la que después de 16 meses de funcionamiento había sido diluida en enero de ese año (A. Guerra Borges, comunicación personal, 25 de noviembre de 2012). Ese año publicó la obra Nutriología ¿Cómo alimentarnos? ¿Por qué? (Guatemala, Tipografía Nacional, 1946) y al año siguiente, Historia del maíz (Guatemala, Imprenta Universitaria, 1947$)^{8}$. La primera carta guatemalteca de su padre que posee doña Rafaela es del 21 de noviembre de 1948, en la que comentaba:

La verdad es que he pasado una temporada muy mediana en mis asuntos de trabajo que me quitó las ganas de todo y llevo varios meses sin escribir ni una sola carta. Felizmente acaban de arreglarse las cosas por lo menos por unos meses y vuelvo de nuevo a la vida recobrando las ganas de escribir (R. de Buen López, comunicación personal, julio de 2014).

Sobre Chile, le comentaba:

Los que lo conocen hablan muy bien de Santiago, desde luego es mucho mejor que estas tierras donde me ha tocado vivir, y donde tiene uno tiempo de aburrirse, siempre con la esperanza de que las cosas de España se arreglen, pero las cosas más faltantes pasan, que no podemos hacernos muchas ilusiones por ahora. Mi vida por estas tierras no puede ser más monótona, la ciudad tiene sólo unos 200 mil habitantes, pero a causa de los terremotos está formada por casas de un solo piso y tiene así poco aspecto monumental, son raras las casas de dos pisos y una docena de ellas de tres. El clima es lo mejor y felizmente en este sentido me ha sentado bien, ya que respecto a la salud no puedo quejarme, aunque no pasan los años en vano. El trabajo es difícil, ya que no son muchos los recursos para poder hacer algo, además los extranjeros es difícil que encontremos las mismas facilidades que los del país para cualquier puesto y la falta de inamovilidad de los cargos, hace que esté uno siempre expuesto, que es lo que me pasó últimamente... De los demás no he sabido nada, tan sólo de Sadí [de Buen López], que está trabajando en El Salvador con éxito. Todos los que vienen de ahí me hablan muy bien de él, que está muy contento con su labor. Siempre fue Sadí formal y trabajador de manera que no me extraña ni me alegran sus éxitos $(R$. de Buen López, comunicación personal, julio de 2014).

$8 \quad$ Agradezco a Marta Elena Casellas del Centro de Investigaciones Regionales de Mesoamérica (CIRMA) el haberme proporcionado la bibliografía guatemalteca de Rafael de Buen Lozano. 
Rafael era el mayor de los hermanos De Buen Lozano. Le seguían Víctor, Fernando, Demófilo, Eliseo y Sadí, padre del sobrino referido. Para entonces, Rafael de Buen Lozano era miembro del Sindicato de Trabajadores del Pensamiento, como también lo eran sus paisanas Leonor de Tejada, profesora de francés, que había llegado a Guatemala el año de 1948 en el programa de inmigración para republicanos españoles residentes en Francia del presidente Arévalo, así como la pedagoga catalana María Solà de Sellerès, directora del Instituto Belén de la ciudad de Guatemala. Entre los guatemaltecos que participaban estaban el pintor Jacobo Rodríguez Padilla y el escritor Miguel Ángel Vásquez, director de la revista Viento Nuevo (J. Rodríguez Padilla, comunicación personal, 7 de mayo de 2013). El 25 de diciembre de 1949, Rafael de Buen le comentaba a su hija:

Algo te extrañará que haya tardado en contestar a tu última carta del 11 de mayo, pues te habrás dado cuenta de que me he vuelto un poco perezoso. Es para mí una gran tranquilidad saber que Héctor y Mario [sus hijos] han logrado salir de España donde la vida es cada día más difícil y se hayan reunido a ti [en Chile]. Me alegran también la buena de que Mario después de un tratamiento ha sido dado de alta en su molestia de la pleura, de todas maneras debería hacerse reconocer de cuando en cuando. También a mí me gustaría mucho poderlos hacer una visita, pero estos se hayan muy lejos de Chile y además de ser muy caro no tengo tiempo libre para el viaje, aunque ahora por ejemplo estoy de vacaciones en la Universidad [de San Carlos] y en el Instituto Diplomático Consular, donde doy clases. No puedo abandonar otros trabajos yendo, cómo el de asesor de Instituto de Fomento de la Producción. Podéis estar tranquilos con respecto a mí, no tened preocupación (R. de Buen López, comunicación personal, julio de 2014).

En julio de 1948 había sido creado por el gobierno arevalista el Instituto de Fomento de la Producción (INFOP) y De Buen Lozano pasó a laborar en él hasta llegar a ser su director. Doña Rafaela comenta que "ninguno de mis tres hermanos [Pedro, Héctor y Mario], rompieron, nunca más quisieron saber de su padre y yo dije bueno, ha tenido defectos, ha tenido cosas que no me gustan, lo que hizo, pero es mi padre al fin y al cabo". "En Caracas, cuando estaba en Venezuela fui a verlo, a él nada más. No tuvieron familia que yo sepa, no creo, no creo, porque siempre alguien te lo cuenta. Asimismo, fui a Montevideo, porque vi que mi tío Fernando, hermano de mi padre, estaba entonces viviendo y trabajando en Montevideo y fui a pasar unas vacaciones con él, que también era biólogo marino" (R. de Buen López, comunicación personal, julio de 2014).

El 25 de junio de 1950, Rafael de Buen Lozano volvió a escribirle a su hija, señalándole que en cinco años de residencia en Guatemala "sólo he salido una vez, a pasar dos meses en La Habana, invitado por la Universidad para dar un curso de verano. Antes viajaba mucho pero desde que llegué a estas tierras me he vuelto sedentario". Luego, el $1^{\circ}$ de octubre de ese año, agregaba:

En el Instituto de la Producción donde estoy haciendo el estudio de la riqueza minera del país y dedicado a la organización pesquera. Por la tarde tengo mis clases y otras ocupaciones, imposible faltar al quehacer, estoy desde hace 
unos meses escribiendo un libro de biología que quiero terminar este mes. Así como comprenderás no me da tiempo para aburrirme... Ahora podré descansar un poco porque ya este mes termino las plazas en la Universidad y en el Instituto Diplomático, y siempre lo notaré un poco. De todas maneras estoy ligado con el cargo de asesor técnico del Instituto de Fomento de la Producción... No me extraña que en tus primeros intentos de hacer deporte de nieve, te hayas dado una serie de batacazos, recuerdo que lo mismo me pasó cuando hice mis primeros intentos aunque se aprende muy rápidamente. Aquí la nieve es desconocida, desde que salí de México no he vuelto a verla; a Guatemala la llaman "el país de la eterna primavera” (Entrevista Rafaela de Buen López, Santiago de Chile, julio de 2014).

Resultado del primer tema de investigación mencionado en la carta es el Estudio sobre el aprovechamiento de los carbones minerales de Guatemala (Guatemala, s. e., 1950), mientras que la obra a la que se refiere es: El hombre a través de la biología (Guatemala, Editorial de Educación Pública. Colección Científico-pedagógica no. 7. 1953).

A lo largo de los años de separación, doña Rafaela no perdió el contacto con su padre, aunque este le escribiese una o dos cartas por año. A finales de 1951, ella le anunció que se iba a casar con Joan Jordana, quien al igual que ella había llegado como refugiado a Chile, pero en el barco Florida. Para entonces era ingeniero de profesión. Su padre le contestó al respecto el 1 de enero del 1952:

Te deseo la mayor felicidad, veo por las fotografías que mi nuevo yerno es buen mozo, me alegra que sea español [era catalán]... Cuéntame detalles, estoy un poco aislado de la vida de la familia ya que únicamente me escribe alguna vez Odón [su sobrino], me comunicó su matrimonio y ahora ha llegado su felicitación de año nuevo, no me da noticias de todos, de manera que eres la única que de vez en cuando me informa de los acontecimientos de la múltiple sobrinería (R. de Buen López, comunicación personal, julio de 2014).

El 4 de agosto de 1952, le comenta sobre su soledad: "Aunque a veces se haya retrasado un poco, me he mantenido felizmente a través de estos años en que las circunstancias nos han mantenido separados ( R. de Buen López, comunicación personal, julio de 2014). El 8 de junio de ese mismo año, Rafael de Buen Lozano notifica a su hija que desde Panamá le habían enviado los papeles de:

un nuevo poder la testamentería de papá y mamá. Primero me lo retrasaron, después exigió el cónsul unos papeles que querían para solucionar unos papeles españoles de cuando murió mi padre, en vista de ello me lo han devuelto pensado que tal vez pudieras tú arreglar las cosas, como lleva autenticación de la firma del notario o del cónsul de Panamá, lo único que falta es que el cónsul o ministro embajador de Panamá en esa, autentifique la firma del señor y luego el cónsul de España auntentique sobre la verdad” (R. de Buen López, comunicación personal, julio de 2014).

Su madre había fallecido el año de 1941 en Banyuls, Francia y el padre en la ciudad de México, en 1945, país a donde se había trasladado en 1942 


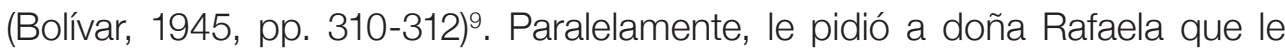
ayudase con trámites para tal efecto, que ella alcanzó a hacer. En la misma carta le comentaba:

Ya te dirá tu amiga Roser [Bru y Llop, quien lo fue a ver a Guatemala], que trabajo en un bonito sitio y que tengo en él un buen puesto. Estoy contento con mi trabajo y tengo en él un sueldo decentito. Me hizo el efecto de que me encontraron físicamente mejor de lo que pensaba y efectivamente aún no tengo la salud estable, gracias sin duda a la vida tranquila y bien atendida que llevo, aunque no voy a dejar de acordarme como es la frecuencia de nuestra tierra, de los sitios en los que he trabajado ya en este continente, en Guatemala donde más me han atendido y donde mejor me encuentro (Bolívar, 1945, pp. 310-312).

Luego, el 26 de octubre de 1952, agregaba:

He tenido últimamente muchísimo trabajo, entre otras cosas me encargaron llevar la organización de todos los trabajos de una reunión internacional [Seminario Centroamericano de Crédito Agrícola auspiciado por la CEPAL], que se ha celebrado aquí y me tuvieron más de un mes ocupado en ello, más de doce horas por día... Pocas novedades puedo contarte de mi vida, ni siquiera he salido de la capital hace tiempo y el tiempo siempre igual dedicado a mi trabajo. Me paso toda la semana con mi labor en el Instituto de Fomento de la Producción y mis clases en la Universidad, y los sábados por la tarde y domingo no salgo nunca de la casa y me dedico a descansar y leer o a hacer algún trabajo especial que a veces tengo (Bolívar, 1945, pp. 310-312).

El 4 de enero de 1953 informaba nuevamente de su situación: "Me alegro que te gustara el recuerdo de estas tierras que te llevó la señora Delia de Barahona. Yo creo que no me acordaba de ella, han pasado ya más de 20 años, y yo tenía un amigo mío que se llamaba Barahona, pero no tiene nada que ver con esto parece". La última carta desde Guatemala es del 4 de enero de 1954 y comentaba:

Para mí, por ejemplo, todos los días se parecen, ya que llevo una vida muy tranquila y ordenada. De casa al trabajo, de nuevo a casa, otra vez a trabajar y a salir a las 5:30 de la tarde cuando no tengo clase en la Universidad. A veces, dar una vuelta al Centro Español Republicano [sic] que sirve de unión para el grupito que estamos aquí, no muy numeroso ni demasiado avenido, como pasa siempre [entre 1946 y 1951 se habían afiliado a la Casa de la República de Guatemala, 150 socios entre residentes de larga data en el país y los refugiados que empezaron a llegar al país a partir de 1945]... Espero la llegada final del ejemplar de mi última obra, que también debe de tener tres o cuatro meses. Por ahora me van a publicar otra, una biología para hacer una enseñanza en Cuba. Aunque aquí los libros no producen nada, por lo menos me han servido de entretenimiento y distracción en escribirlos. Siempre agradable dejar alguna obra en vida (Bolívar, 1945, pp. 310-312).

$9 \quad$ En ese número también se recoge el homenaje al científico de la Unión de Profesores Universitarios españoles y el Ateneo Ramón y Cajal (p. 275). Véase también: Puig y Samper Mulero, 2001, pp. 95-125. 
Lejos estaba de pensar que año y medio después tendría que asilarse con su compañera en la embajada de México debido a la caída del presidente Jacobo Arbenz. El 14 de septiembre de 1954, De Buen Lozano le escribió ya desde México a su hija:

Te pongo solo unas líneas para comunicarte que estoy perfectamente y me encuentro en esta capital de México. Mi nueva dirección es Liverpool 110, segundo, México, DF.

Los acontecimientos de Guatemala me obligaron, con otros 84 republicanos españoles, a asilarme en la Embajada de México, donde hemos permanecido más de dos meses totalmente incomunicados de manera que no me fue posible escribirle a nadie, ni recibir ninguna visita. Después nos llevaron en avión a la frontera de México, desde [donde] venimos en tren, en un viaje muy pesado de dos días.

Tuve que abandonar mi casa premeditadamente dejándome todo lo que tenía, de manera que ahora me toca empezar de nuevo y rehacer mi vida. Espero tener suerte y poder arreglar las cosas satisfactoriamente.

Ya te escribiré más despacio, pero no he querido dejar pasar los días sin darte noticias pues supongo estarías intranquila sobre mi suerte.

Un fuerte abrazo de tu padre, Rafa (Archivo Personal de Rafaela de Buen López, Carta de Rafael de Buen Lozano, México, 14 de septiembre de 1954, 1 fol) ${ }^{10}$.

El 26 de diciembre de ese año, le explicaba que había posibilidades de que abandonase México para volver a Francia:

Ahora ya puedo informarte de lo que va a ser de mí. Varios amigos de Francia estaban haciendo gestiones para buscarme allí un trabajo y felizmente se ha resuelto ya todo de forma satisfactoria. En vista de ello pienso salir para allí antes del fin de enero [1955] y te enviaré mi nueva dirección cuando quede instalado. Hace tiempo que tenía deseos de volver a Europa, por lo que ya me encuentro cansado de andar de un lado a otro por estas tierras y para mi carrera científica conviene muchísimo más. Al fin veo cumplidos estos deseos y no creo que volvería más por estas tierras... Desde luego, lo de Guatemala fue muy desagradable. Además, perdí todo lo que tenía y especialmente lo siento por mi biblioteca, que era bastante importante y para mí constituye un medio de trabajo necesario. Pero, qué le vamos hacer y lo principal es haber salido sin mayores dificultades ( $R$. de Buen López, comunicación personal, julio de 2014).

El 14 febrero de 1955, frente al Palacio Nacional y como homenaje a la visita a Guatemala del vicepresidente estadounidense Richard Nixon, el gobierno de Castillo Armas planificó la quema pública de "literatura sovietizante"11. Según los datos dados por la Secretaría de la Presidencia, habían sido confiscadas 40 toneladas de libros, equivalentes a 3.000.000 de obras. Entre el material quemado estaban las bibliotecas de los republicanos españoles, el editor Bartomeu Costa-Amic y los doctores Rafael de Buen Lozano y Antonio Román Durán,

10 Archivo Personal de Rafaela de Buen López, Carta de Rafael de Buen Lozano, México, 14 de septiembre de 1954, 1 fol. Elfaro) y (Los libros que Castillo Armas quemó para Nixon, 2015, 15 de febrero, El Periódico). 
así como las de varias Facultades de la Universidad de San Carlos. Asimismo, fueron quemadas las ediciones de la Revista de Guatemala, de la Revista Saker-ti, de la revista El Maestro, las obras de Juan José Arévalo, Luis Cardoza y Aragón, Guillermo Toriello Garrido, Manuel Galich y de otros intelectuales de la Revolución de Octubre. Además, por su puesto, toda la literatura referente a los principales ideólogos marxistas, Marx, Engel, Lenin y Stalin, más la propaganda llegada desde el campo socialista.

Al final, los planes de emigrar a Francia no se cumplieron y Rafael de Buen permaneció en México hasta diciembre de 1958, cuando se desplazó a Venezuela para impartir clases en la Universidad Nacional. Luego de la caída del dictador Marcos Pérez Jiménez se habían sucedido en la presidencia Wolfang Larrazábal y Edgar Sanabria, quienes operaron una apertura del régimen político, facilitando la llegada de nuevos republicanos españoles. Sanabria se distinguió, además, por concederle a la Universidad de Venezuela la autonomía. En carta de 10 de junio de 1959, fechada en Caracas, le informaba a doña Rafaela que:

debido a tener bastante alta la presión arterial en México, no me sentaba del todo bien a causa de la altura. Por otra parte, amigos de aquí me escribieron que me viniera, ya que había una serie de proyectos para organizar estudios marinos y la pesca, y tenían interés de que les ayudara. En vista de ello he decidido rápidamente emprender el viaje y desde fines del año pasado me encuentro aquí... Pronto aprobarán las Cortes una ley de reforma agraria y el Instituto Agrario se transformará en Instituto de Reforma Agraria. Como en Costa Rica y en Guatemala trabajé ya en los problemas de producción, me puedo desenvolver perfectamente en mi trabajo (R. de Buen López, comunicación personal, julio de 2014).

En 1962 regresó a México, donde fue catedrático de la Universidad de Morelia. También fue secretario de la Unión de Intelectuales en México y miembro del Consejo Español de la Paz hasta que la muerte lo sorprendió en esa ciudad por un paro cardíaco el 30 de mayo de 1966. El rector Lic. Alberto Bremauntz publicó la siguiente esquela:

LA UNIVERSIDAD MICHOACANA DE SAN NICOLAS DE HIDALGO

Hace público su estado de duelo por el fallecimiento del distinguido catedrático Doctor Rafael del Buen, director del Instituto de Investigación Científica, fundador y primer director de la Facultad de Altos Estudios "Melchor Ocampo", dependiente de esta universidad; acaecido a las 22 horas del día 30 del actual. Morelia, Mich., a 31 de Mayo de 1966 (Bremauntz, 1 de junio de 1966, p. 13)12.

\section{Palabras finales}

La intensa vida en América de Rafael de Buen Lozano no solo es una constatación de la "España peregrina" como en 1940 José Bergamín y sus compañeros refugiados en México conceptualizaron al exilio republicano, sino

12 Agradezco a la Mtra. Sol Ortiz el haberme proporcionado esta necrología. 
también del destino trágico de la vida de este gran científico y político español. Un destino trágico que no estuvo al margen de la tragedia que la Guerra Fría abrió en América Central en la década de 1950 con la caída del presidente Jacobo Arbenz y el fin del régimen democrático guatemalteco que inauguró la Revolución de Octubre de 1944. Militancia, profesión, trabajo y vida personal se entremezclan para un asilado republicano español con los acontecimientos políticos del país o los países en que decidió o pudo residir. A su vez, en medio de un exilio español que habría de experimentar muchas fracturas de orden político, ideológico y generacional por efecto de las derrotas político-militares y de la influencia de los poderes hegemónicos surgidos de la Guerra Fría.

\section{Referencias}

Amo, Julián y Chramion Shelby. (1950). La obra impresa de los intelectuales españoles en América, 1936-1945. Prólogo de Alfonso Reyes. Stanford: Stanford University Press.

Archivo Personal de Rafaela de Buen López. Carta de Rafael de Buen Lozano, Sierra de Madrid, 20 de septiembre de 1937, 1 fol.

Archivo Personal de Rafaela de Buen López. Carta de Rafael de Buen Lozano, México, 14 de septiembre de 1954, 1 fol.

Archivo Personal de Rafaela de Buen López. "Cuba y Puerto Rico" (dibujo a mano), [Barcelona, 1938].

Archivo General de la Administración, España. Libro de Actas de la Casa de la República Española. M456-461 (actual 12/3064) JARE. Acta No. 42, fols. 31 y 32, 5 de diciembre de 1946.

Baumann, Gino. (2009). Los voluntarios latinoamericanos en la guerra civil española. Cuenca: Ediciones de la Universidad de Castilla-La Mancha.

Bolívar Pieltain, Cándido. (1945, 20 de diciembre). Odón De Buen, Ciencia, VII(7-9), 310-312.

Bremauntz, Alberto. (1 de junio de 1966). La Voz de Michoacán, p. 13.

Cal Montoya, José. (2015, 25 de agosto). Los libros que la CIA quemó en Guatemala, Elfaro. Recuperado de http://www.elfaro.net/es/201508/academico/17306/Los-libros-que-la-CIA-quem\%C3\%B3-en-Guatemala.htm

Cazali Ávila, Augusto. (2001). Historia de la Universidad de San Carlos de Guatemala. Época republicana, 1821-1944. Guatemala: Editorial Universitaria.

De Mónaco, Alberto. (marzo, 2012). Rafael de Buen Lozano. En Centro de Estudios Odón de Buen. Recuperado de http://www.odondebuen. org/2012/03/13/1949/ 
Fundación Pablo Iglesias. (s.f.). Buen Lozano, Rafael de. En Diccionario Biográfico del Socialismo Español. Recuperado de http://www.fpabloiglesias.es/archivo-y-biblioteca/diccionario-biografico/biografias/3070_buen-lozano-rafael

Giral, Francisco. (1994). Ciencia española en el exilio (1939-1989): el exilio de los científicos españoles. Barcelona: Anthropos-Madrid: Centro de Investigaciones y Estudios Republicanos.

Guerra, Francisco. (2003). La medicina en el exilio republicano. España: Universidad de Alcalá de Henares.

La Universidad Michoacana de San Miguel Hidalgo. (1966, 1 de junio). La Voz de Michoacán, Morelia, Michoacán, México, 13.

Luján Muñoz, Luis. (1994). La Revolución del 20 de Octubre de 1944 y los republicanos españoles en Guatemala, Encuentro, 14. Guatemala: Instituto Guatemalteco de Cultura Hispánica, 45-62.

Oliva Medina, Mario. (2008). Los intelectuales y las letras centroamericanas sobre la Guerra Civil española. México: Centro de Investigaciones sobre América Latina y el Caribe-Universidad Nacional Autónoma de México.

PHhistory: Los libros que Castillo Armas quemó para Nixon. (2015, 15 de febrero). El Periódico. Recuperado de http://bdc.elperiodico.com.gt/ es/20150215/domingo/8573/PBHistory-Los-libros-que-Castillo-Armasquem\%C3\%B3-para-Nixon.htm

Puig-Samper Mulero, Miguel Ángel. (2001). La Revista Ciencia y las primeras actividades de los científicos españoles en América. En Agustín Sánchez Andrés y Silvia Figueroa Zamudio (eds.), De Madrid a México. El exilio español y su impacto sobre el pensamiento de la ciencia y el sistema educativo mexicano. México: Universidad Michoacana de San Nicolás de HidalgoComunidad de Madrid, 95-125.

Taracena Arriola, Arturo. (2014). La polémica entre Eugenio Fernández Granell, la AGEAR y el Grupo Saker-ti: Desencuentros ideológicos durante la 'primavera' democrática guatemalteca. Guatemala: Facultad Latinoamericana de Ciencias Sociales.

Vrsalovic, Verena. (2004, 23 de febrero). El beneficio de escribir mirando hacia atrás, El Mercurio. Recuperado de http://diario.elmercurio.com/detalle/index.asp?id=\{8d2ca796-f8b3-4f67-954b-4655376bec67 $\}$ 